\title{
Kinetic and Mechanistic Study of Oxidation of Piperazines by Bromamine-T in Acidic Medium
}

\author{
Chandrashekar $^{1,2}$, B. M. Venkatesha ${ }^{1^{*}}$, S. Ananda ${ }^{3}$, Netkal M. Made Gowda ${ }^{4 *}$ \\ ${ }^{1}$ Department of Chemistry, Yuvaraja's College, University of Mysore, Mysore, India \\ ${ }^{2}$ Department of Chemistry, PES College of Engineering, Mandya, India \\ ${ }^{3}$ Department of Studies in Chemistry, Manasagangothri, University of Mysore, Mysore, India \\ ${ }^{4}$ Department of Chemistry, Western Illinois University, Macomb, USA \\ Email: "venkichem123@yahoo.in, "gn-made@wiu.edu
}

Received December 25, 2012; revised April 24, 2013; accepted September 14, 2013

Copyright (C) 2013 Chandrashekar et al. This is an open access article distributed under the Creative Commons Attribution License, which permits unrestricted use, distribution, and reproduction in any medium, provided the original work is properly cited.

\begin{abstract}
Oxidations of piperazine, 1-methylpiperazine and 1-ethylpiperazine by bromamine-T (BAT) in buffered acidic medium have been kinetically studied at $303 \mathrm{~K}$. The reaction shows a first-order dependence of the rate each on $[\mathrm{BAT}]_{0}$ and [piperazine $]_{0}$, and an inverse fractional-order dependence on $\left[\mathrm{H}^{+}\right]$. The additions of halide ions and the reduction product of BAT, $p$-toluenesulfonamide, have no effect on the reaction rate. The variation of ionic strength of the solvent medium has no influence on the rate. Activation parameters have been evaluated from the Arrhenius and Eyring plots. A common mechanism consistent with the kinetic data has been proposed for all piperazines. The protonation constants of substrates have been evaluated. The Hammett linear free-energy relationship has been observed for the reaction with $\rho=-0.5$ indicating that the electron-donating groups enhance the reaction rate by stabilizing the transition state. An isokinetic relationship observed shows $\beta=368 \mathrm{~K}$ indicating the dominance of enthalpy factors on the reaction rate.
\end{abstract}

Keywords: Piperazines; Oxidation Kinetics; Mechanism; Bromamine-T; Buffer

\section{Introduction}

Piperazine is a heterocyclic nitrogenous compound [1] that has chemical similarity with piperidine as it has two opposing nitrogen atoms in the ring. In animals, including man, piperazine and its salts are known to be highly effective as anthelmintics [2]. It is used in the treatment of gout and is an excellent solvent for uric acid $[2,3]$. Many uses of piperazine derivatives have been suggested [4]. Their more important use is as intermediates for tranquilizing agents and antihistamines, insecticides, fungicides, bactericides, analgesics, antispasmodics, filaricides and anthelmintics. Some piperazines have been investigated for the treatment of cancer [5,6], radiation sickness [7], and anginapectoris [8]. The literature survey shows that the kinetic investigations of reactions of piperazines with iron (II) and cobalt (III) have been reported by Aravindakshan et al. [9]. Aromatic N-halosulfonamides are mild oxidants containing a strongly polarized Nhalogen bond where the halogen is in its +1 oxidation state. The prominent member of this group, chloramine- $T$ (CAT), is a well-known analytical reagent and the me-

\footnotetext{
${ }^{*}$ Corresponding authors.
}

chanistic aspects of many of its reactions have been documented $[10,11]$. Its bromine analogue, bromamine- $T$ (BAT), is a better oxidizing agent than CAT and chloramine-B. However, meager information exists in the literature on BAT-piperazines reactions [12-15]. Hence, the oxidation kinetics of piperazines adds much to the knowledge of redox chemistry. These facts prompted us to undertake the study of kinetics of oxidation of piperazines by BAT in acidic buffer medium with a view to elucidate the reaction mechanism.

\section{Experimental}

The oxidant BAT was prepared and purified using the method of Nair and Indrasenan [16]. Its purity was checked by iodometric and spectroscopic data $[16,17]$. Aqueous solutions of BAT were prepared, standardized by the iodometric method, and preserved in amber-colored bottles until use, to prevent its photochemical deterioration. Piperazines (Spectrochem Co.) of acceptable grades of purity were used without further purification. Fresh aqueous solutions of piperazines were prepared whenever required. All other chemicals used were of ac- 
ceptable grades of purity. A constant ionic strength of the reaction mixture was maintained at $0.1 \mathrm{~mol} \cdot \mathrm{dm}^{-3}$ by adding a concentrated $\mathrm{NaClO}_{4}$ solution. Triply distilled water was employed for preparing aqueous solutions. A $\mathrm{pH} 4.0$ buffer solution of acetic acid and sodium acetate was prepared [18] and its $\mathrm{pH}$ value checked with a $\mathrm{pH}$ meter.

\subsection{Kinetic Measurement}

The kinetic runs were performed under pseudo-first-order conditions of $[\text { piperazine }]_{0}>>[\mathrm{BAT}]_{0}$ at $303 \mathrm{~K}$. For each run, requisite amounts of solutions of the piperazine, $\mathrm{NaClO}_{4}$ and buffer of known $\mathrm{pH}$ were taken in stoppered Pyrex glass tube whose outer surfaces were coated black to eliminate photochemical effects. A required amount of $\mathrm{pH} 4.0$ acetate buffer solution was added to maintain a constant total volume for all runs. The tube was thermostated in a water bath set at a given temperature. To this solution was added a measured amount of preequilibrated BAT solution to give a known overall concentration. The reaction mixture was periodically shaken for uniform concentration. The progress of the reaction was monitored by withdrawing aliquots of the reaction mixture at regular time intervals and by iodometrically titrating the unreacted BAT for over two half-lives. The pseudo-firstorder rate constants $\mathrm{k}^{\prime}$ calculated were reproducible within $\pm 3.0 \%$. The regression analysis of experimental data was carried out on an Origin 5.0 HP computer to obtain the regression coefficient, $r$.

\subsection{Stoichiometry}

Varying ratios of the oxidant-to-piperazine in $\mathrm{pH} 4.0$ buffer were equilibrated at $303 \mathrm{~K}$ for $24 \mathrm{~h}$. The unreacted $\mathrm{BAT}$ in the reaction mixture determined iodometrically showed that one mole of piperazine reacted with one mole of BAT to give the corresponding N-oxide, which is stoichiometrically represented as in Equation (1).

Here $\mathrm{R}=\mathrm{H}$ for piperazine, $\mathrm{CH}_{3}$ for 1-methylpiperazine and $\mathrm{C}_{2} \mathrm{H}_{5}$ for 1-ethylpiperazine;

$$
\mathrm{Ar}=p-\mathrm{Me}-\mathrm{C}_{6} \mathrm{H}_{4} \text {. }
$$

\subsection{Product Analysis}

The reaction mixture in the stoichiometric ratio in the presence of buffer medium was allowed to progress for $24 \mathrm{hr}$ at $303 \mathrm{~K}$. After completion of the reaction (monitored by TLC), the reaction mixture was neutralized and the products were extracted with diethyl ether. The organic products were subjected to spot tests and TLC analysis. The $\mathrm{N}$-oxide products corresponding to piperazine oxide, 1-methylpiperazine oxide and 1-ethylpiperazine oxide were confirmed by GC-MS analysis. Mass spectral data for the N-oxide products were obtained on a 17A Shimadzu gas chromatograph with LCMS - 2010A Shimadzu mass spectrometer. For example, the mass spectrum showed a parent molecular ion peak at $102 \mathrm{amu}$ (Figure 1) confirming the formation of piperazine $\mathrm{N}$ oxide in the reaction mixture of piperazine and BAT. The reaction product, $p$-toulenesulphonamide $\left(\mathrm{ArSO}_{2} \mathrm{NH}_{2}\right)$, was detected by paper chromatography [19]. Benzyl alcohol saturated with water was used as the solvent with $0.5 \%$ vanillin in $1 \% \mathrm{HCl}$ in ethanol as the developing reagent $\left(\mathrm{R}_{\mathrm{f}}=0.905\right)$.

\section{Results and Discussion}

The stiochiometry of BAT oxidation of piperazine and its derivatives was found to be of 1:1 mole ratio. Oxidations of piperazines by BAT were kinetically investigated, under pseudo-first order conditions of [piperazine $]_{0}>>$ $[\mathrm{BAT}]_{0}$, at several initial concentrations of reactants in pH 4.0 buffer medium. Under comparable experimental

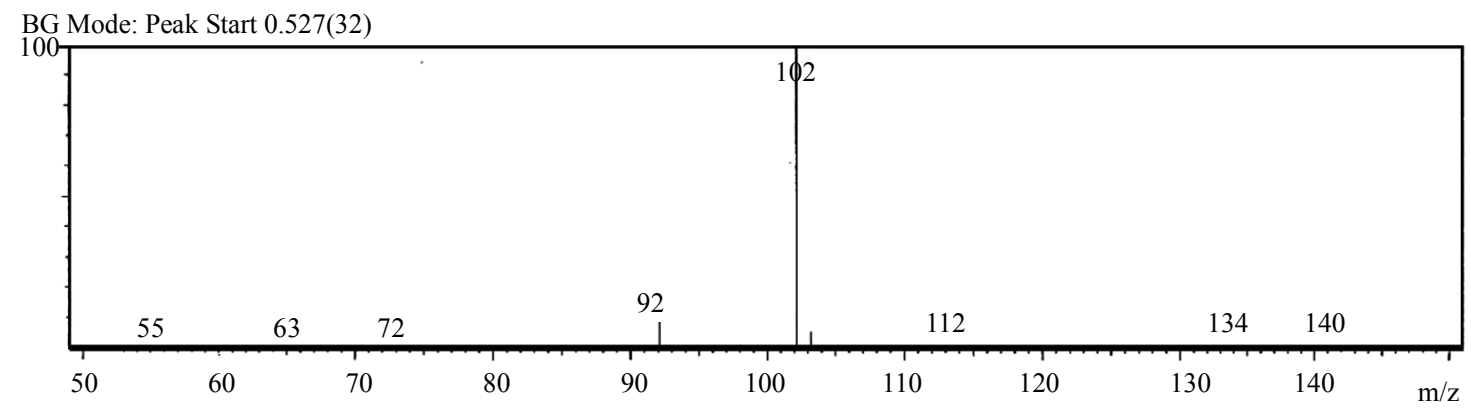

Figure 1. Mass spectrum of piperazine-N-oxide with its molecular ion peak at $102 \mathrm{amu}$.

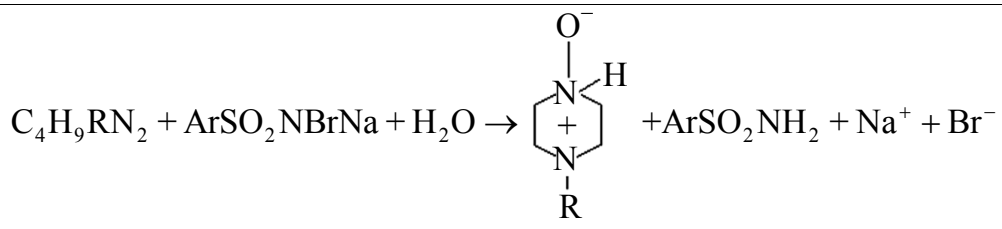


conditions, a similar oxidation kinetic behavior was observed for all piperazines.

\subsection{Effect of Varying Reactant Concentrations on the Rate}

The reaction performed in $\mathrm{pH} 4.0$ buffer medium gave linear plots of $\ln [\mathrm{BAT}] v s$ time $(\mathrm{r}>0.9948)$. The linearity of these plots together with the constancy of the slope for various $[\mathrm{BAT}]_{0}$ indicated a first-order dependence of the reaction rate on [BAT]. The pseudo-first-order rate constants, $\mathrm{k}^{\prime}$, obtained at $303 \mathrm{~K}$ are listed in Table 1. Under the same experimental conditions, an increase in [piperazine $]_{0}$ increased the rate. Plots of $\operatorname{lnk}^{\prime} v s$ $\ln [\text { piperazine }]_{0}$ were linear $(r>0.9948)$ with slopes of 0.992, (piperazine) 0.995, (1-methylpiperazine) and 1.00 (1-ethylpiperazine), which indicated a general first-order dependence of the rate on the [substrate].

\subsection{Effect of Acid on the Rate}

The reaction rate increased with increasing $\mathrm{pH}$ (Table 2) and plots of $\operatorname{lnk} k^{\prime} v s \ln \left[\mathrm{H}^{+}\right]$were linear $(\mathrm{r}>0.9961)$ with negative fractional slopes $(-0.67$ to -0.75$)$ showing an inverse fractional order dependence of the rate on $\left[\mathrm{H}^{+}\right]$ for each piperazine reaction.

\subsection{Effets of Ionic Strength and $\mathrm{ArSO}_{2} \mathrm{NH}_{2}$ on the Rate}

The addition of $\mathrm{Cl}^{-}$ions in the form of $\mathrm{NaCl}$ at constant $\mathrm{pH}$ and ionic strength, did not affect the rate. Hence the dependence of the rate on $\mathrm{pH}$ reflected the net effect of $\left[\mathrm{H}^{+}\right]$. The variation of ionic strength of the reaction medium effected using $\mathrm{NaClO}_{4}\left(0.10-0.50 \mathrm{~mol} \mathrm{dm}{ }^{-3}\right)$, while keeping all other experimental conditions the same, had no effect on the rate. Furthermore, the addition of $p$-toluenesulfonamide or $\mathrm{ArSO}_{2} \mathrm{NH}_{2}\left(3.0 \times 10^{-4}-7.0 \times\right.$ $10^{-4} \mathrm{~mol} \cdot \mathrm{dm}^{-3}$ ) had no effect on the rate indicating that it is not involved in a pre-equilibrium to the rate determining step.

\subsection{Effect of Temperature on the Rate}

The reaction was studied at different temperatures in the range, $298 \mathrm{~K}$ to $313 \mathrm{~K}$, while keeping the concentrations of reactants and other experimental conditions constant. The rate constants are presented in Table 3. The activation parameters (Table 3) were calculated from the slopes and intercepts of Arrhenius and Eyring plots of $\log \mathrm{k}^{\prime}$ vs $1 / \mathrm{T}$ and $\log \mathrm{k}^{\prime} / \mathrm{T}$ vs $1 / \mathrm{T}(>\mathrm{r}-0.9826)$, respectively.

\subsection{Test for Free Radicals}

Addition of the reaction mixtures to aqueous acryl amide monomer solutions, in the dark, did not initiate polymerization/precipitation, indicating the absence of in situ formation of free radical species in the reaction sequence.

\subsection{Mechanism}

Bromamine- $\mathrm{T}\left(\mathrm{ArSO}_{2} \mathrm{NBrNa} \cdot 3 \mathrm{H}_{2} \mathrm{O}\right)$, like its chlorine analog chloramine-T (CAT), behaves as an electrolyte in aqueous solutions [20] dissociating to furnish an anion (Equation (2)). This anion undergoes protonation in acid medium to form the free acid, $\mathrm{ArSO}_{2} \mathrm{NHBr}$, as in Equation (3). Although the free acid has not been isolated, the conductometric studies of CAT have provided ample evidence of its formation [20,21]. In acid medium, the

Table 1. Effect of varying reactant concentrations on the reaction rate $\mathrm{pH}=4.0$; temperature $=303 \mathrm{~K}$.

\begin{tabular}{ccccc}
\hline \multirow{2}{*}{$0^{4}[\mathrm{BAT}]\left(\mathrm{mol} \cdot \mathrm{dm}^{-3}\right)$} & $10^{2}[\text { Piperazine }]_{0}\left(\mathrm{~mol} \cdot \mathrm{dm}^{-3}\right)$ & $\mathrm{k}^{\prime} \times 10^{4}\left(\mathrm{~s}^{-1}\right)$ & \\
\cline { 3 - 5 } 3.00 & 1.00 & Piperazine & 1-Methylpiperazine & 1-Ethylpiperazine \\
\hline .00 & 1.00 & 2.23 & 3.96 & 6.15 \\
5.00 & 1.00 & 2.20 & 3.98 & 6.00 \\
6.00 & 1.00 & 2.18 & 3.90 & 6.10 \\
7.00 & 1.00 & 2.16 & 3.97 & 6.20 \\
5.00 & 5.00 & 2.25 & 3.88 & 3.14 \\
5.00 & 7.00 & 1.20 & 2.04 & 4.26 \\
5.00 & 10.00 & 1.52 & 2.63 & 6.00 \\
5.00 & 12.0 & 2.18 & 3.90 & 7.23 \\
5.00 & 15.0 & 2.57 & 4.57 & 9.43 \\
5.00 & 20.0 & 3.65 & 5.83 & 12.7 \\
\hline
\end{tabular}


Table 2. Effect of varying $\mathrm{pH}$ on the reaction rate [piperazine $]_{0}=1.00 \times 10^{-2} \mathrm{~mol} \cdot \mathrm{dm}^{-3} ;[\text { BAT }]_{0}=5.00 \times 10^{-4}$ $\mathrm{mol} \cdot \mathrm{dm}^{-3}$; temperature $=303 \mathrm{~K}$.

\begin{tabular}{ccccc}
\hline $\mathrm{pH}$ & $\begin{array}{c}10^{5}\left[\mathrm{H}^{+}\right] \\
\left(\mathrm{mol} \cdot \mathrm{dm}^{-3}\right)\end{array}$ & \multicolumn{4}{c}{$\mathrm{k}^{\prime} \times 10^{4}\left(\mathrm{~s}^{-1}\right)$} \\
\hline 3.6 & 25.1 & 1.14 & 1.90 & 2.95 \\
3.8 & 15.9 & 1.62 & 2.63 & 3.99 \\
4.0 & 10.0 & 2.18 & 3.90 & 6.00 \\
4.2 & 6.30 & 3.02 & 5.88 & 8.22 \\
4.4 & 3.98 & 4.16 & 8.51 & 10.96 \\
4.6 & 2.51 & 4.90 & 12.3 & 14.80 \\
\hline
\end{tabular}

free acid undergoes a reaction to form dibromamine- $\mathrm{T}$ or DBT $\left(\mathrm{ArSO}_{2} \mathrm{NBr}_{2}\right)$ and $p$-toluenesulfonamide

$\left(\mathrm{ArSO}_{2} \mathrm{NH}_{2}\right.$ ) (Equation (4)). $\mathrm{ArSO}_{2} \mathrm{NHBr}$ hydrolyzes to give $\mathrm{HOBr}$ as one of the products [Equation (5)]. In high acid concentrations, $\mathrm{HOBr}$ can get protonated to $\mathrm{H}_{2} \mathrm{OBr}^{+}$ as in Equation (6).

$$
\begin{gathered}
\mathrm{ArSO}_{2} \mathrm{NBrNa} \rightleftharpoons \mathrm{ArSO}_{2} \mathrm{NBr}^{-}+\mathrm{Na}^{+} \\
\mathrm{ArSO}_{2} \mathrm{NBr}^{-}+\mathrm{H}^{+} \rightleftharpoons \mathrm{ArSO}_{2} \mathrm{NHBr} \\
2 \mathrm{ArSO}_{2} \mathrm{NHBr} \rightleftharpoons \mathrm{ArSO}_{2} \mathrm{NBr}+\mathrm{ArSO}_{2} \mathrm{NH}_{2} \\
\mathrm{ArSO}_{2} \mathrm{NHBr}+\mathrm{H}_{2} \mathrm{O} \rightleftharpoons \mathrm{ArSO}_{2} \mathrm{NH}_{2}+\mathrm{HOBr} \\
\mathrm{HOBr}+\mathrm{H}^{+} \rightleftharpoons \mathrm{H}_{2} \mathrm{OBr}^{+}
\end{gathered}
$$

In acidic solutions, the probable oxidizing species are the free acid $\left(\mathrm{ArSO}_{2} \mathrm{NHBr}\right), \mathrm{ArSO}_{2} \mathrm{NBr}_{2}$ and $\mathrm{HOBr}$. The involvement of $\mathrm{ArSO}_{2} \mathrm{NBr}_{2}$ in the mechanism leads to a second-order rate law, which is contrary to the experimental observations, as Equation (4) indicates. If a slow hydrolysis of $\mathrm{ArSO}_{2} \mathrm{NHBr}$ occurred as in Equation (5), leading to $\mathrm{HOBr}$ as the primary oxidizing species, a firstorder retardation of the rate by the added $\mathrm{ArSO}_{2} \mathrm{NH}_{2}$ would be expected. This is contrary to the experimental results. Hardy and Johnston [22], who have studied the $\mathrm{pH}$-dependence of relative concentrations of the species present in acidified chloramine- $\mathrm{T}$ solutions of comparable molarities, have shown that $\mathrm{ArSO}_{2} \mathrm{NHBr}$ is the likely oxidizing species in acid medium.
Furthermore, ultraviolet spectral measurements showed that the aqueous piperazine solutions have a sharp absorption band at $235 \mathrm{~nm}$, while the BAT solution exhibits a peak around $287 \mathrm{~nm}$, both in $\mathrm{pH} 4.0$ buffer solutions and water. A mixture of BAT and piperazine shows a $\lambda_{\max }$ around $330 \mathrm{~nm}$ which indicates no direct reaction between $\mathrm{BAB}$ and piperazines and no deprotanation from BAB. However, piperazine in $\mathrm{pH} 4.0$ buffer exhibits a $\lambda_{\max }$ at $380 \mathrm{~nm}$, which shows a longer shift indicating the formation of intermediate $S^{\prime}$ due to deprotanation of the substrate. Based on the preceding discussion, Scheme 1 below is proposed for the reaction.

A detailed common mode of oxidation of piperazines by BAT in acidic buffer medium along with structures of intermediates is depicted in Scheme 2.

\subsection{Rate Law Derivation}

From the slow step of Scheme 1,

$$
\text { Rate }=k_{2}\left[S^{\prime}\right][B A T]
$$

From step (1),

$$
\left[\mathrm{S}^{0}\right]=\frac{\left\lfloor\mathrm{S}^{\prime}\right\rfloor\left[\mathrm{H}^{+}\right]}{K_{1}}
$$

Also,

$$
[\mathrm{S}]_{t}=\left[\mathrm{S}^{0}\right]+\left[\mathrm{S}^{\prime}\right]
$$

Combination of Equations (8) and (9) leads to Equa-

\begin{tabular}{|c|c|c|c|c|c|c|c|c|}
\hline \multirow{2}{*}{ Substrate } & \multicolumn{4}{|c|}{$\mathrm{k}^{\prime} 10^{4}\left(\mathrm{~s}^{-1}\right)$} & \multirow{2}{*}{$\frac{\Delta \mathrm{H}^{\neq}}{\left(\mathrm{kJ} \mathrm{mol}^{-1}\right)}$} & \multirow{2}{*}{$\frac{\Delta \mathrm{S}^{\ddagger}}{\left(\mathrm{JK}^{-1} \mathrm{~mol}^{-1}\right)}$} & \multirow{2}{*}{$\frac{\Delta \mathrm{G}^{\neq}}{\left(\mathrm{kJ} \mathrm{mol}^{-1}\right)}$} & \multirow{2}{*}{$\frac{\mathrm{Ea}}{\left(\mathrm{kJ} \mathrm{mol}^{-1}\right)}$} \\
\hline & 298 & 303 & 308 & 313 & & & & \\
\hline Piperazine & 1.47 & 2.18 & 3.38 & 7.41 & 79.0 & -55.6 & 95.4 & 81.6 \\
\hline 1-Methylpiperazine & 2.61 & 3.90 & 6.45 & 10.7 & 71.0 & -76.0 & 94.16 & 73.5 \\
\hline 1-Ethylpiperazine & 3.71 & 6.0 & 8.77 & 12.6 & 60.2 & -106.6 & 92.7 & 62.7 \\
\hline
\end{tabular}
tion $(10)$

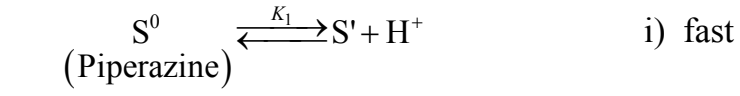

$$
\begin{aligned}
& \mathrm{S}^{\prime}+\mathrm{ArSO}_{2} \mathrm{NHBr} \stackrel{\mathrm{k}_{2}}{\longrightarrow} \underset{\text { (complex) }}{\mathrm{X}}+\mathrm{ArSO}_{2} \mathrm{NH}^{-} \text {ii) slow } \\
& \mathrm{X}+\mathrm{H}_{2} \mathrm{O} \longrightarrow \text { Products } \\
& \left(\mathrm{ArSO}_{2} \mathrm{NH}^{-}+\mathrm{H}^{+} \longrightarrow \mathrm{ArSO}_{2} \mathrm{NH}_{2}\right) \\
& \text { iii) fast } \\
& \text { Here } \mathrm{Ar}=p-\mathrm{Me}-\mathrm{C}_{6} \mathrm{H}_{4}
\end{aligned}
$$

Scheme 1. General mechanism for the oxidation of piperazines by BAT in pH 4 buffer.

Table 3. Effect of varying temperature and activation parameters for the oxidation of piperazines by BAT in acidic buffer $[\text { piperazine }]_{0}=1.00 \times 10^{-2} \mathrm{~mol} \cdot \mathrm{dm}^{-3} ;[\mathrm{BAT}]_{0}=5.00 \times 10^{-4} \mathrm{~mol} \cdot \mathrm{dm}^{-3} ; \mathrm{pH}=\mathbf{4 . 0}$. 
i)

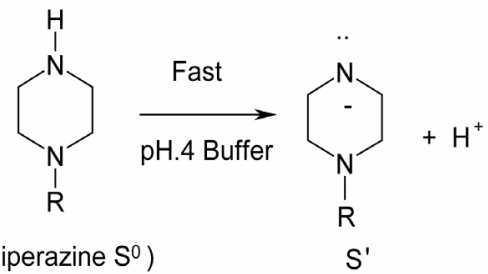

$\left(\mathrm{R}=\mathrm{H}, \mathrm{CH}_{3}, \mathrm{C}_{2} \mathrm{H}_{5}\right)$

ii)

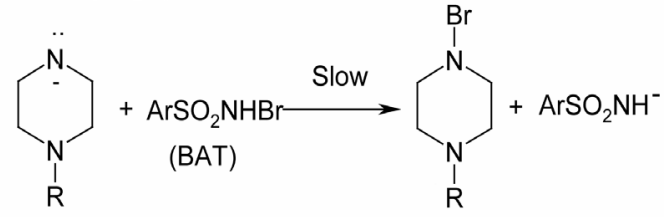

iii)

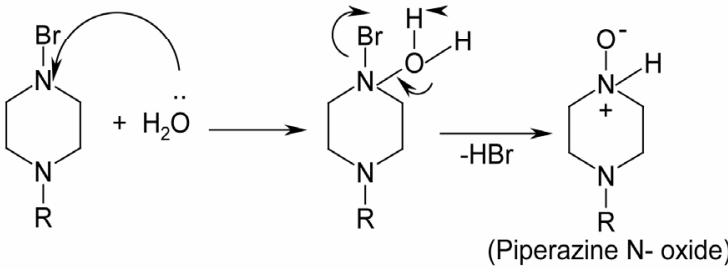

iv) $\mathrm{ArSO}_{2} \mathrm{NH}^{-}+\mathrm{H}^{+} \longrightarrow \mathrm{ArSO}_{2} \mathrm{NH}_{2}$

Scheme 2. Detailed reaction pathway for the oxidation of piperazines by BAT in acidic medium.

$$
\begin{gathered}
{[\mathrm{S}]_{t}=\frac{\left[\mathrm{S}^{\prime}\right]\left[\mathrm{H}^{+}\right]}{K_{1}}+\mathrm{S}^{\prime}=\frac{\left[\mathrm{S}^{\prime}\right]\left\{\left[\mathrm{H}^{+}\right]+K_{1}\right\}}{K_{1}}} \\
{\left[\mathrm{~S}^{\prime}\right]=\frac{K_{1}[\mathrm{~S}]_{t}}{\left[\mathrm{H}^{+}\right]+K_{1}}}
\end{gathered}
$$

Substitution for S' in Equation (7) leads to,

$$
\text { rate }=\frac{K_{2} K_{1}[\mathrm{~S}]_{t}[\mathrm{BAT}]}{\left[\mathrm{H}^{+}\right]+K_{1}}
$$

The rate law (Equation (11)) obtained from Scheme 1 is in good agreement with the experimental results, where the rate has a first-order dependence each on $[\mathrm{BAT}]_{0}$ and [substrate piperazine $]_{0}$ and an inverse fractional-order on $\left[\mathrm{H}^{+}\right]$.

Since, rate $=k^{\prime}[B A T]$, Equation (11) can be transformed as,

$$
\mathrm{k}^{\prime}=\frac{\mathrm{k}_{2} K_{1}[\mathrm{~S}]_{t}}{\left[\mathrm{H}^{+}\right]+K_{1}}
$$

Or

$$
\frac{1}{\mathrm{k}^{\prime}}=\frac{\left[\mathrm{H}^{+}\right]}{\mathrm{k}_{2} K_{1}[\mathrm{~S}]_{t}}+\frac{1}{\mathrm{k}_{2}[\mathrm{~S}]_{t}}
$$

Based on Equation (12), plots of $1 / \mathrm{k}^{\prime} v s\left[\mathrm{H}^{+}\right]$at constant $[\mathrm{BAT}]_{0}$, [piperazine $]_{0}$ and temperature have been found to be linear (Figure 2, r > 0.9951) for all piperazines. The deprotonation constants $\left(K_{1}\right)$ and protanation

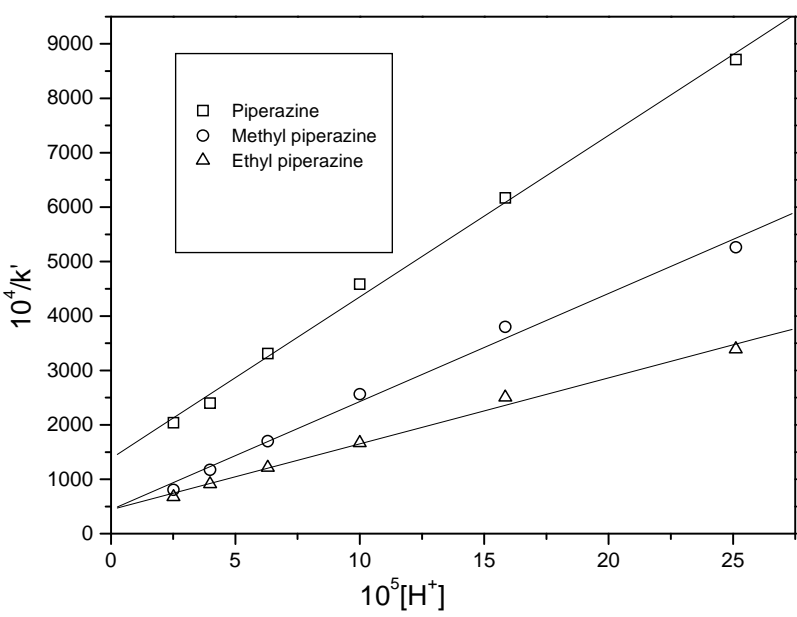

Figure 2. Reciprocal plots of $1 / \mathbf{k}^{\prime}$ vs $\left[\mathbf{H}^{+}\right]$Experimental conditions are as in Table 2.

constants $\left(K_{P}\right)$ of the substrate and the reaction constant $\left(\mathrm{k}_{2}\right)$ were calculated from the slope and intercept of these plots for the standard runs with $[\mathrm{BAT}]_{0}=5.00 \times 10^{-4} \mathrm{~mol}$ $\mathrm{dm}^{-3}$, [piperazine $]_{0}=1.00 \times 10^{-2} \mathrm{~mol} \mathrm{dm}$, and $\left[\mathrm{H}^{+}\right]=$ $1.00 \times 10^{-4} \mathrm{~mol} \mathrm{dm}^{-3}$ at $303 \mathrm{~K}$. Furthermore, the values of protonation constant of the substrate $\left(K_{P}=1 / K_{1}\right)$ determined are presented in Table 4.

\subsection{Structure-Reactivity Correlation}

Structural modification of a reactant molecule may influence the rate or equilibrium constant of a reaction through inductive, polar, steric and resonance effects, which can be used to probe into the reaction mechanism. Out of a number of empherical models proposed in describing the relationship between structure and reactivity, the most successful and extensively investigated is the linear free energy relationship [23] with Hammett equation as the most prominent example. Hammett treatment describes the substituent effects on the rate and equilibria of aromatic molecules. In the present system, structurereactivity relationship is ascertained by utilizing different groups $\left(\mathrm{H}, \mathrm{CH}_{3}, \mathrm{C}_{2} \mathrm{H}_{5}\right)$ at one of the two nitrogens $\left(\mathrm{N}_{1}\right)$ of the piperazine ring and tested to fit results into the Hammett equation [24]. The Hammett plot of $\log \mathrm{k}^{\prime}$ vs $\sigma$ is reasonably linear $(r=-0.9957)$. From such a plot, the value of the reaction constant $\rho$ is found to be -0.52 signifying that the electron releasing groups in the piperazine ring enhance the rate. The positive inductive effect of the substituent increases the electron density on nitrogen of the piperazine ring system and subsequently the lone electron pair on nitrogen nucleophilically attacks the positive bromine end of the reactive oxidizing species, $\mathrm{ArSO}_{2} \mathrm{NHBr}$, to form the N-bromopiperazine transition state (Scheme 2). In the next fast step, the bromopiperazine intermediate undergoes hydrolysis to yield piperazine-N-oxide as the end product. Furthermore, the posi- 
Table 4. Protonation and deprotonation constants for the oxidation of piperazines by BAT in acidic medium at $303 \mathrm{~K}$.

\begin{tabular}{cccc}
\hline Substrate & $10^{-5} K_{1}\left(\mathrm{~mol} \cdot \mathrm{dm}^{-3}\right)$ & $10^{4} K_{P}\left(\mathrm{dm}^{3} \cdot \mathrm{mol}^{-1}\right)$ & $\mathrm{k}_{2}\left(\mathrm{dm}^{3} \cdot \mathrm{mol}^{-1} \mathrm{~s}^{-1}\right)$ \\
\hline Piperazine & 4.65 & 2.14 & 0.072 \\
1-Methylpiperazine & 2.21 & 4.51 & 0.226 \\
1-Ethylpiperazine & 3.64 & 2.74 & 0.226 \\
\hline
\end{tabular}

tive inductive effect of the substituent in the piperazine ring system increases in the order: $\mathrm{H}<\mathrm{CH}_{3}<\mathrm{C}_{2} \mathrm{H}_{5}$, which justifies the observed reactivity trend of piperazine $<1$-methylpiperazine $<1$-ethylpiperazine.

\subsection{Isokinetic Relationship}

The largest activation energy for the slowest reaction (Table 3) indicates that the reaction is enthalpy controlled, within the reaction series. The variation in the rate may be caused by changes in either the enthalpy or entropy of activation or both. In this study, enthalpy and entropy of activation are correlated by $\Delta \mathrm{H}^{\neq}=\Delta \mathrm{H}_{0}^{\neq}+$ $\beta \Delta \mathrm{S}^{\neq}$, which is called the isokinetic relationship where $\beta$ is the isokinetic temperature. When the experimental temperature $\mathrm{T}<\beta$, the reaction rate is controlled mainly by the enthalpy change. In the present case, the piperazines oxidations are linearly related by plotting $\Delta \mathrm{H}^{\neq} v s \Delta \mathrm{S}^{\neq}$ (Figure 3, r $=0.9995)$. From the slope, the value of isokinetic temperature $(\beta)$ is computed to be $368 \mathrm{~K}$. The determined $\beta$ value of $368 \mathrm{~K}$ being higher than the experimental temperature of $303 \mathrm{~K}$, suggests that the reaction is enthalpy controlled. The existence of isokinetic relationship is very valuable to the mechanistic chemist as this can be used as a supportive evidence for the mechanism along with other data. The large negative value of $\Delta \mathrm{S}^{\neq}$indicates a more ordered associative transition state with less degree of freedom. The near constant $\Delta \mathrm{G}^{\neq}$ values show an identical common mechanistic pathway in the oxidation of all the piperazines studied. Further-

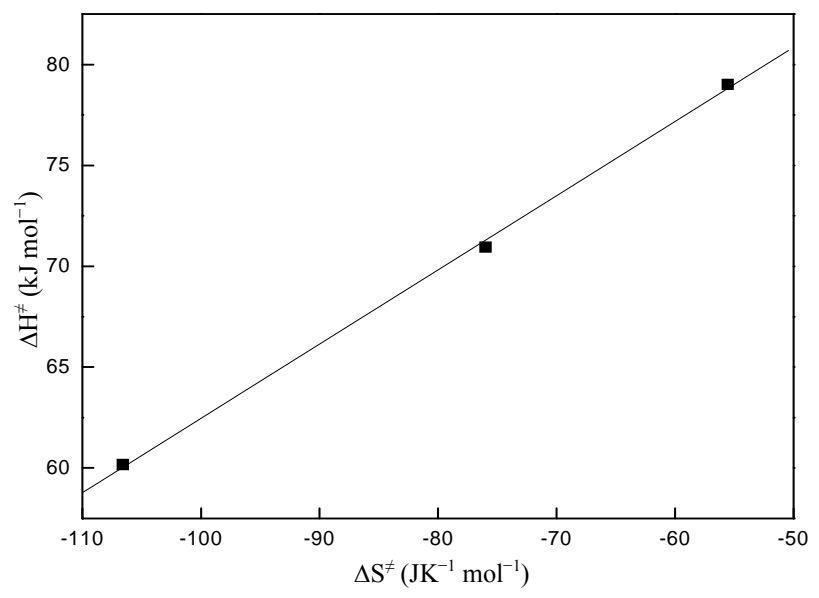

Figure 3. Isokinetic plot of $\Delta \mathbf{H}^{\ddagger} v s \Delta \mathbf{S}^{\neq}$. more, the independent nature of the rate towards the addition of $p$-toulenesulfonamide, halide ion and neutral salts supports the proposed mechanism and the rate law derived.

\section{Conclusion}

Kinetics of oxidation of three piperazines using Bromamine-T as the oxidant was carried out in acid medium. A mechanism has been proposed and the rate law has been derived. The Hammett correlation of the substituent effect shows a linear free energy relationship with $\rho=$ -0.52 indicating that electron-donating centers enhance the rate of reaction. An isokinetic study indicates that enthalpy rather than entropy factors controls the reaction rate.

\section{Acknowledgements}

Chandrashekar thanks the management of PES College of Engineering, Mandya, Karnataka for granting permission to undertake this study and for encouragement.

\section{REFERENCES}

[1] W. R. Maynard Jr., "Gravimetric and Infra-Red Spectrophotometric Determination of Piperazine," Journal of the Association of Official Analytical Chemists, Vol. 42, 1961, pp. 610-612.

[2] G. L. Crenshaw and R. J. Shaver, "Down to Earth," Dow Chemical Company, Michigan, 1956.

[3] L. S. Goodman and A. Gilman, "The Pharmacological Basis of Therapeutics," 2nd Edition, Macillan Company, New York, 1956.

[4] R. M. Ioset, "Personal Communication," Dow Chemical Company, Midland, Michigan, 1961.

[5] T. J Mc Nair, F. A. Wibin, E. T. Hoppe, J. L. Schmidt and F. A. de Peyster, "Antitumor Action of Several New Piperazine Derivatives Compared to Certain Standard Anticancer Agents," Journal of Surgical Research, Vol. 3, No. 3, 1963, pp. 130-136. http://dx.doi.org/10.1016/S0022-4804(63)80014-1

[6] V. A. Mikhalev, M. I. Dorokhova and N. E. Smolina, "Prospidine and Some Other Derivatives of Steropoly Piperazine," Meditsinskaia promyshlennost' SSSR, Vol. 17, No. 1, 1963, pp. 17-20.

[7] W. O. Foye and D. H. Kay, "Antiradiation Compounds III. N-2-Mercaptoethylpiperazines" Journal of Pharma- 
ceutical Sciences, Vol. 51, No. 11, 1962, pp. 1098-1101. http://dx.doi.org/10.1002/jps.2600511120

[8] A. Jouve, A. Grass and R. Benyamine, "Hemodynamic Studies during Angina Pectoris," Vie Med., Vol. 44, 1963, pp. 115-120.

[9] K. K Aravindakshan and K. Muraleedharan, "Kinetics of Non-Isothermal Decomposition of Polymeric Complexes of N,N'-Bis(dithiocarboxy)piperazine with Iron(III) and Cobalt(III)" Thermochimica Acta, Vol. 159, 1990, pp. 101-107.

http://dx.doi.org/10.1016/0040-6031(90)80098-J

[10] M. M. Campbell and G Johnson, "Chloramine T and Related N-Halogeno-N-Metallo Reagents," Chemical Reviews, Vol. 78, No. 1, 1978, pp. 65-79. http://dx.doi.org/10.1021/cr60311a005

[11] K. K. Banerji, B. Jayaram and D. S. Mahadevappa, "Mechanistic Aspects of Oxidations by N-Metallo-NHaloarylsulfonamides," Journal of Scientific \& Industrial Research, Vol. 46, 1987, pp. 65-76.

[12] F. Ruff and A. F. Kucsman, "Oxidation of Dialkylsulhides with BAT in Alkaline Buffer Solutions," Journal of the Chemical Society, Perkin Transactions II, 1990, p. 1075.

[13] D. S. Mahadevappa and Puttaswamy, "Kinetics of Oxidation of Aliphatic Ketones with Bromamine-T in Acid Medium," Bulletin of the Chemical Society of Japan, Vol. 61, No. 2, 1988, pp. 543-547. http://dx.doi.org/10.1246/bcsj.61.543

[14] K. S. Rangappa, H. Ramachandra, D. S. Mahadevappa and N. M. Made Gowda, "Osmium (VIII) Catalyzed Kinetics and Mechanism of Indoles Oxidation with Aryl-NHaloamines in Alkaline Medium," International Journal of Chemical Kinetics, Vol. 28, No. 4, 1996, pp. 265-274. http://dx.doi.org/10.1002/(SICI)1097-4601(1996)28:4<26 5::AID-KIN4>3.0.CO;2-T

[15] Puttaswamy and R. Ramachndrappa, "Ruthenium(III)Catalyzed Oxidation of Substituted Ethanols by Sodium N-Bromo-p-Toluenesulfonamide in Hydrochloric Acid Medium," Transition Metal Chemistry, Vol. 24, No. 3, 1999, pp. 326-332.
http://dx.doi.org/10.1023/A:1006931803005

[16] C. G. R Nair and P Indrasenan, "New Redox Titrants in Non-Aqueous or Partially Aqueous Media-VI ${ }^{1}$ : Potentiometric Determinations Using Dibromamine-T and Some Further Applications of Dichloramine-T," Talanta, Vol. 23, No. 3, 1976, pp. 239-241. http://dx.doi.org/10.1016/0039-9140(76)80178-6

[17] M. S. Ahmed and D. S. Mahadevappa, "Bromamine-B as a New Oxidimetric Titrant," Talanta, Vol. 27, No. 8, 1980, pp. 669-670.

http://dx.doi.org/10.1016/0039-9140(80)80207-4

[18] R. M. C. Dawson, D. C. Elliott, W. Elliott and K. M. Jones, "Data for Biochemical Research," 3rd Edition, Oxford Science Publications, 1986.

[19] D. S. Mahadeveppa and N. M. Made Gowda, "Estimation of Glutathione with Chloramine-T and Dichloramine-T," Talanta, Vol. 22, No. 9, 1975, pp. 771-773. http://dx.doi.org/10.1016/0039-9140(75)80226-8

[20] E. Bishop and V. J. Jennings, "Titrimetric analysis with chloramine-T-I: The status of chloramine-T as a titrimetric reagent," Talanta, Vol. 1, No. 3, 1958, pp. 197212. http://dx.doi.org/10.1016/0039-9140(58)80034-X

[21] D. S. Mahadevappa and Rangaswamy, "Physico Chemical Properties of Chloramine-T. II. Conductometric study of the Interaction of Chloramine-T with Chromium(III), Aluminium(III) and Iron(III) Solutions," Revue Roumaine de Chimie, Vol. 22, 1977, pp. 1233-1241.

[22] F. F Hardy and J. P. J Johnston, "The Interactions of $N$ Bromo- $N$-Sodiobenzenesulphonamide (Bromamine-B) with $p$-Nitrophenoxide Ion," Journal of the Chemical Society, Perkin Transactions II, No. 6, 1973, pp. 742-746.

[23] R. D Gilliom, "Introduction to Physical Organic Chemistry", Addison Wesley, London, 1970, p. 144.

[24] L. P. Hammett, "The Effect of Structure upon the Reactions of Organic Compounds. Benzene Derivatives," Journal of the American Chemical Society, Vol. 59, No. 1, 1937, pp. 96-103. http://dx.doi.org/10.1021/ja01280a022 